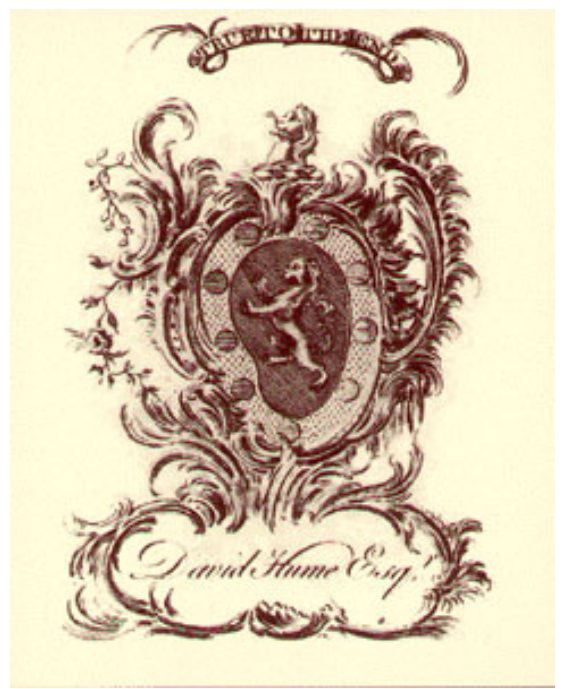

\title{
Filling the Gaps in Hume's Vacuums
}

Miren Boehm

Hume Studies Volume 38, Number 1 (2012), 79-99.

Your use of the HUME STUDIES archive indicates your acceptance of HUME STUDIES' Terms and Conditions of Use, available at http : //WWW . humesociety . org/hs/about/terms . html.

HUME STUDIES' Terms and Conditions of Use provides, in part, that unless you have obtained prior permission, you may not download an entire issue of a journal or multiple copies of articles, and you may use content in the HUME STUDIES archive only for your personal, non-commercial use.

Each copy of any part of a HUME STUDIES transmission must contain the same copyright notice that appears on the screen or printed page of such transmission. For more information on HUME STUDIES contact humestudies-info@humesociety.org

http://www.humesociety.org/hs/ 


\title{
Filling the Gaps in Hume's Vacuums
}

\author{
MIREN BOEHM
}

\begin{abstract}
The paper addresses two difficulties that arise in Treatise 1.2.5. First, Hume appears to be inconsistent when he denies that we have an idea of a vacuum or empty space yet allows for the idea of an "invisible and intangible distance." My solution to this difficulty is to develop the overlooked possibility that Hume does not take the invisible and intangible distance to be a distance at all. Second, although Hume denies that we have an idea of a vacuum, some texts in Treatise 1.2.5 are taken by interpreters to suggest that Hume nonetheless believes that there are vacuums in nature. I discuss the relevant texts and defend the view that Hume does not in fact countenance belief in vacuums. I conclude by outlining an interpretation of Hume's intention in the Treatise that allows us to understand his discussion of ideas as having implications for the sciences.
\end{abstract}

Treatise 1.2.5 opens with a simple argument against the idea of a vacuum: "If [it is] true, that the idea of space or extension is nothing but the idea of visible or tangible points distributed in a certain order; it follows, that we can form no idea of a vacuum, or space, where there is nothing visible or tangible" (T 1.2.5.1; SBN 53). ${ }^{1}$ In Treatise 1.2.3 Hume argues that the idea of space or extension is the idea of a disposition of colored or solid points, and in Treatise 1.2.4 he already concludes that "'tis impossible to conceive ... a vacuum" (T 1.2.4.2; SBN 39). But other things Hume writes in Treatise 1.2.5 compel us to question these results. Indeed, as I shall argue, Treatise 1.2.5 not only forces us to confront much of what Hume attempts to establish in

Miren Boehm, Assistant Professor, Department of Philosophy, University of WisconsinMilwaukee, PO Box 413, Milwaukee, WI 53201. Email: boehmm@uwm.edu. 
Treatise 1.2, it also raises fundamental methodological questions about Hume's project in the Treatise.

In this paper I address two difficulties that arise in Treatise 1.2.5. First, although Hume repeatedly denies in Treatise 1.2 that we have an idea of a vacuum, indeed, he claims that a vacuum is inconceivable, in Treatise 1.2.5 he introduces the idea of what he refers to as "the invisible and intangible distance" (T 1.2.5.16; SBN 59). But how is the idea of an invisible and intangible distance different from the idea of a vacuum, or empty space? Although the text suggests that Hume takes these ideas to be different, it is not clear at all how they can be different. For Hume, the idea of space and the idea of extension are one and the same. For instance, in the passage quoted above, he refers to the "idea of space or extension," and he claims that it is "nothing but the idea of visible or tangible points distributed in a certain order" (T 1.2.5.1; SBN 53). Hume also claims that we get the idea of extension when we consider the distance between bodies: "Upon opening my eyes, and turning them to the surrounding objects, I perceive many visible bodies; and upon shutting them again, and considering the distance betwixt these bodies, I acquire the idea of extension" (T 1.2.3.2; SBN 33; my emphasis). When we consider the distance between bodies in this case, we consider colored points disposed in a certain manner. This is because "my senses convey to me only the impression of colour'd points, disposed in a certain manner" (T 1.2.3.4; SBN 34). Thus it seems that for Hume the idea of space, the idea of extension, and the idea of distance are one and the same: each is the idea of colored or tangible points distributed in a certain order. And indeed, Hume explicitly identifies distance with extension and space when he calls distance "real extension" and claims that it is "mark'd out by compounded and sensible objects (T 1.2.5.17; SBN 59). But this distance is just one of "two kinds of distance" he distinguishes (T 1.2.5.17; SBN 59). The other distance he introduces is the "invisible and intangible distance" (T 1.2.5.17; SBN 59).

The first problem I address in this paper arises from the following apparently unavoidable line of reasoning: If one kind of distance is "real extension," or space, or colored or tangible points distributed in a certain manner, then the other kind of distance, the invisible and intangible distance, must be a distance, extension, or space devoid of visible or tangible points. But the idea of a space devoid of sensible objects just is the idea of a vacuum, or empty space. Thus Hume's "invisible and intangible distance" appears to be another name for empty space, or a vacuum. If this is the case, then his account of our idea of space, or extension, as necessarily the idea of a continuous array of colored or solid points is mistaken.

The second difficulty arises from a common interpretation of Hume's attitude toward vacuums in nature. Interpreters claim that despite his denial of the idea of a vacuum, despite the fact that he insists that a vacuum is inconceivable, Hume allows for the existence of vacuums in nature. Some even assert that he is "inclined to believe" that there are vacuums in nature. ${ }^{2}$ But how is it possible for Hume to 
deny that we have an idea of $\mathrm{x}$ and yet allow for the existence of $\mathrm{x}$ and believe in the existence of $\mathrm{x}$ ? And what is the point of denying that we can have an idea of a vacuum if it does not prevent Hume or anyone from postulating vacuums in nature $?^{3}$ These questions naturally prompt a more general inquiry into Hume's examination of ideas in the Treatise and his aims. Is the investigation into the nature of our ideas meant to have any bearing on the other sciences, such as mathematics and natural philosophy? Or is the Hume of the Treatise engaged mainly in a descriptive science of mind, what he calls in the Enquiry "mental geography": the mere "delineation of the distinct parts and powers of the mind" (EHU 1.13; SBN 13)?

My strategy is as follows. First, I discuss Hume's introduction of the idea of the "invisible and intangible distance" in the context of his denial of the idea of a vacuum. I examine and criticize several interpretations whose main tactic is to argue that the invisible and intangible distance is a distance but not empty space or extension without matter. I then propose a novel interpretation: I argue that the idea of an invisible and intangible distance is not at all the idea of a distance and, therefore, that it is not the idea of empty space, or extension devoid of visible or tangible points. I then offer an account of the nature of Hume's idea of an invisible and intangible distance. Second, I discuss the problematic texts, and I reject the view that Hume allows that there are vacuums in nature and that he believes in them. Third, I connect the popular view that Hume allows for the possibility of vacuums in nature to an influential programmatic interpretation of his project in the Treatise, namely a reading that conceives of Hume as primarily engaged in a descriptive science of the mind. In contrast to this reading, I put forth the view that Hume's denial of the idea of a vacuum is meant to have implications for natural philosophy; in particular, I discuss what I take to be the implications for Newtonian philosophy. I argue that this interpretation fits with the ambition Hume announces in the introduction to the Treatise, namely to establish the sciences on a solid and secure foundation. Hume's science of mind is the foundation for the other sciences, and he is carrying out this foundational work in the Treatise.

\section{I}

In Treatise 1.2.5 Hume sets out to consider three objections to his denial of the idea of a vacuum. First, if we talk about vacuums, we must have an idea of a vacuum. Second, a vacuum is at least possible because it is conceivable, that is, because we can, indeed, form an idea of a vacuum or an idea of empty space. Third, the idea of a vacuum is necessary for explaining motion. Motion without a vacuum would be impossible; since there is motion, there must be vacuums. Hume proceeds to address these objections by examining "the nature and origin of several ideas, lest we dispute without understanding perfectly the subject of the controversy" (T 1.2.5.5; SBN 55). And to examine our ideas Hume sets out to trace them back 
to actual or possible impressions. He does so by considering a number of thought experiments.

Hume first discusses utter darkness as a candidate impression for generating the idea of empty space or a vacuum. He compares a sighted person exposed to utter darkness with a blind person. A sighted person "receives no other perception from turning his eyes on every side, when entirely depriv'd of light than what is common to him with one born blind" (T 1.2.5.5; SBN 55). And a blind person, according to Hume, "has no idea either of light or darkness" (T 1.2.5.5; SBN 55). "The consequence of this is," he reasons, "that 'tis not from the mere removal of visible objects we receive the impression of extension without matter; and that the idea of utter darkness can never be the same with that of vacuum" (T 1.2.5.5; SBN 55). Utter darkness, or the removal of visible objects, cannot generate the idea of a vacuum or extension without matter. Hume also discusses a parallel thought experiment for the tangible, which involves motion and aims to show that someone devoid of all tangible sensations could not form the idea of empty space. Thus he concludes, "darkness and motion, with the utter removal of every thing visible and tangible, can never give us the idea of extension without matter or of a vacuum" (T 1.2.5.6; SBN 56).

Hume then considers another set of thought experiments and introduces the idea of an invisible and intangible distance. He asks "whether [darkness and motion] can convey [the idea of empty space], when mix'd with something visible and tangible" (T 1.2.5.6; SBN 56). He discusses two cases. The first involves the darkness between "visible luminous bodies" (T 1.2.5.8-12; SBN 56-57), and the second, the non-tangible intervals between tangible sensations (T 1.2.5.9; SBN 56). In what follows, I will essentially focus on Hume's discussion of the first of these two thought experiments, which involves vision. Thus I employ mostly the notion of visibility, but the same points can be made with regard to that of tangibility.

Hume asks us to imagine that "amidst an entire darkness, there are luminous bodies presented to us, whose light discovers only these bodies themselves, without giving us any impression of the surrounding objects" (T 1.2.5.8; SBN 56). In discussing this example Hume distinguishes between "our natural and most familiar way of thinking" and what "a little reflection" will allow us to conclude about this case. According to "our natural and most familiar way of thinking," the darkness between the luminous bodies is a distance: something that has size, "great or small," depending on the position of the bodies and whether they move or not (T 1.2.5.10; SBN 57). The familiar way of thinking also reasons that this distance must be a vacuum, or an empty space. In contrast, Hume's own way of thinking, or "a little reflection," disagrees with the inference that the distance between the luminous bodies must be a vacuum, or "pure extension" (T 1.2.5.10; SBN 57). Hume, however, appears to agree with the familiar point of view that the darkness between the bodies is a distance. 
Throughout Treatise 1.2.5 Hume refers to the darkness between the luminous bodies as a distance. He calls it "the dark and undistinguishable distance" ( $\mathrm{T}$ 1.2.5.11; SBN 57), and also "the invisible and intangible distance" (T 1.2.5.16; SBN 59). He explicitly distinguishes between "two kinds of distance" (T 1.2.5.17-19; SBN 59-60). One distance, as we saw earlier, he refers to as "real extension" which is "mark'd out by compounded and sensible objects" (T 1.2.5.17; SBN 59). This distance, then, is identical to space, or extension. The other distance he identifies is the invisible and intangible distance, which according to Hume, is "known only by the manner, in which distant objects affect the senses" (T 1.2.5.17; SBN 59). The standard interpretation of these texts is that Hume takes the darkness between the luminous bodies to be a distance, a distance which is devoid of visible and tangible points. I shall discuss some of the interpreters who defend this reading and their differences later in the paper. But first, the obvious problem is this: if the invisible and intangible distance is indeed a distance, then how is it not empty space or extension without matter or a vacuum ${ }^{4}$

Donald Baxter considers the idea of an invisible and intangible distance to be indeed the idea of a distance, but he denies that the invisible and intangible distance is empty space, or extension without matter, or a vacuum. On Hume's behalf he argues that "geometry gives the properties of space" and that "space as dealt with in geometry has parts; invisible and intangible distance has no parts." But this is not very satisfying for reasons that Baxter himself should find compelling. Consider Baxter's interpretation of the distinction Hume draws between the "two kinds of distance":

Such a distinction might well seem strange, but it is appropriate if we confine our attention to the world as it appears. We can distinguish distant things between which other things appear, from distant things between which no other things appear. The former distance is "mark'd out by compounded and sensible objects," whereas the latter is "known only by the manner, in which the distant objects affect the senses" (T 1.2.5.17). ... In the world as it appears, the stars are either separated by visible or tangible distance or by invisible and intangible distance, depending, for example, on whether or not the sky is dark. (Baxter, "Hume's Theory of Space and Time," 139)

Baxter maintains that Hume is concerned with "the world as it appears." In the world as it appears, the stars are separated either by invisible and intangible distance or by visible or tangible distance, which is space, or extension.

Although Hume discusses the geometrical properties of space, Hume's space is not only "space as dealt with in geometry," but also space as it appears to us. Indeed, virtually all of the discussion in Treatise 1.2 .5 can be described as a discussion about 
appearances. ${ }^{6}$ Hume starts this section by discussing the natural and familiar way of thinking in terms of how things appear to us; he ends with strict methodological statements about his philosophy of appearances and adds appendices to the section urging us to "confine our speculations to the appearances of objects to our senses" (T 1.2.5.26 note 12; SBN 638-39). Baxter is right to point out that Hume is concerned with the world as it appears, and the world as it appears surely includes space: the very same space that Hume's geometry deals with.

Well into Treatise 1.2.5 Hume offers an account of how we mistake the idea of an invisible and intangible distance for the idea of empty space. Some interpreters have taken this discussion to address the question I am concerned with here, namely the conflict between postulating an idea of invisible and intangible distance while denying the idea of a vacuum. Michael Costa, for instance, points out that for Hume " $[w]$ e do not have a genuine idea of empty space, but we do have an idea of an invisible and intangible distance (T 62)." He continues, "This has the appearance, however, of a mere verbal maneuver."7 To show that it is not a verbal maneuver, Costa invokes Hume's account of abstract ideas and of the mistakes the mind can make when ideas are very similar. Costa remarks, "The problem is that particular complex ideas of invisible distance become connected to dispositions to bring to mind complex ideas of extension, and that particular complex ideas of extension get connected to dispositions to bring to mind complex ideas of invisible distance" ("Strict Identity," 5; emphases in original). Because the idea of an invisible distance is similar to the idea of a visible one, or the idea of extension, the mind takes the idea of an invisible distance to be an idea of extension.

Costa sets out to address the problem we are concerned with here, what he refers to as having the appearance of a "mere verbal maneuver." This is the problem of seeing how the idea of an invisible and intangible distance is different from the idea of empty space (or extension without matter or vacuum). But his "solution" does not address this problem at all. The account Costa offers, which focuses on Treatise 1.2.5, describes the process by which we take the idea of invisible and intangible distance to be the idea of extension (or space). The very presence of this account in Treatise 1.2.5 confirms that Hume wishes to deny that the idea of an invisible and intangible distance is the same as the idea of extension without matter or empty space. This is because the account of the process in question presupposes that the idea of an invisible and intangible distance is not the idea of extension (or space). Thus the account to which Costa calls our attention explains only how, given that the idea of invisible and intangible distance is not the idea of extension, we come to believe that it is. It does not explain how it is that the idea of an invisible and intangible distance is not the same as the idea of a vacuum, or empty space.

Hume wishes to deny that the idea of an invisible and intangible distance is the same as the idea of empty space or extension without matter or a vacuum. 
But how does he defend this denial? I believe that the prospects of explaining how the idea of an invisible and intangible distance is the idea of a distance but not the idea of a vacuum are rather dim. Instead, my proposal is that, for Hume, the idea of an invisible and intangible distance is not the idea of a distance at all. The problem we have been exploring so far arises because we are, quite naturally, interpreting the invisible and intangible distance to be a distance. After all, Hume himself distinguishes between "two kinds of distance," and one of them is the invisible and intangible one. This compels the following interpretation: the difference between visible and tangible distance (or space or extension) and invisible and intangible distance consists in the words that come before the two tokens of "distance." But then we cannot escape the conclusion that invisible and intangible distance is empty space, or a vacuum, because visible and tangible distance is (non-empty) space or extension.

In Treatise 1.2.5 Hume also refers to an "imaginary distance" (T 1.2.5.13; SBN 58) and a "fictitious distance" (T 1.2.5.23; SBN 62). In what follows, I defend the view that he does not take the "invisible and intangible distance" to be a distance (and therefore not space or extension without matter or a vacuum), and I do so by exploring what Hume means by "imaginary" and "fictitious" distance.

Much of the discussion in Treatise 1.2.5 draws on the following important distinction. On the one hand, Hume refers to differences "in the objects themselves" (T 1.2.5.12; SBN 57). On the other hand, he refers to "the manner [the objects themselves] affect our senses" (T 1.2.5.12; SBN 57). And what Hume seems to be distinguishing here is, on the one hand, what is present to the senses, and on the other, the perceivers' reaction to what is present to the senses. The context of his references to imaginary distance and fictitious distance involves in each case a discussion of how perceivers or their organs react to the perceived. Hume refers to "imaginary distance" when he discusses "the sense of feeling" or the sensation of motion we feel from moving from one tangible object to another, which he brings up to illustrate the case of sight and the motion of the eye in its passage from one luminous body to the other. Likewise, he refers to "fictitious distance" when discussing the effects of what is present to the senses or to the "eye" and the "feeling" in his response to the second objection mentioned at the beginning of this paper concerning the conceivability of vacuums and their possibility (T 1.2.5.23; SBN 62; emphasis in original). ${ }^{8}$

Hume insists that the only difference with regard to "the objects themselves" between the case of total darkness and the case of the luminous bodies separated by darkness is the presence of the luminous bodies (T 1.2.5.11-12; SBN 57). This already suggests that if there is no distance in the total darkness case, then there is no distance in the case of the luminous bodies separated by darkness either, at least when we consider only "the objects themselves." But Hume also identifies other 
differences in "the manner [the objects themselves] affect our senses" (T 1.2.5.12; SBN 57). And this is where distance makes its appearance.

Referring to the case of the luminous bodies, Hume writes, "the motion that is requir'd in the eye, in its passage from one to the other; and the different parts of our organs; which are affected by them; these produce the only perceptions, from which we can judge of the distance. But as these perceptions are each of them simple and indivisible, they can never give us the idea of extension" ( $\mathrm{T}$ 1.2.5.12; SBN 57). Hume illustrates the above with "the sense of feeling, and the imaginary distance or interval interpos'd betwixt tangible or solid objects" (T 1.2.5.13; SBN 58). He compares the case of a man supported in the air, moving his limbs "to and fro" without encountering any tangible object, with the case of another man who feels something, "leaves it, and after a motion, of which he is sensible, perceives another tangible object." According to Hume, "the sensation, which arises from the motion, is in both cases the same." He concludes that this sensation "is not capable of conveying to us an idea of extension" (T 1.2.5.12; SBN 57).

I want to focus on the visual case, because it is explicitly about distance and about how we "judge of the distance." In contrast, the tangible case seems only concerned with empty space: it establishes that nothing in the objects themselves, and nothing in our sensations, can generate the idea of (empty) space. I want to concentrate, in particular, on the motion of the eyes as they move from one luminous body to the other. Thus, consider the difference in the movements of the eyes in the case of total darkness or blindness and in the case of the luminous bodies separated by darkness. In the first case, there is nothing in the objects themselves that guides or influences the movement of the eyes. One moves the eyes randomly, as it were. (In the tangible case above, Hume describes the man as "moving his limbs to and fro" (T 1.2.5.12; SBN 57)). But in the case of the luminous bodies, their relative position "guides" the movement of the eyes. The movement is not directionless or random. (Note how Hume describes the case of "interrupted" tangible perception above: "[the man] leaves it, and after a motion, of which he is sensible, perceives another tangible object." In this case also, there is no "to and fro" but rather "a motion").

Hume claims that the movement of the eyes allows us to "judge of the distance." However, he points out that since the perceptions generated by the movements "are each of them simple and indivisible, they can never give us the idea of extension" (T 1.2.5.12; SBN 57). This passage raises two questions: (1) How do we "judge of the distance," that is, what is the process by which we make this judgment, whatever the judgment turns out to be? and (2) If I am right that there is no distance between the luminous bodies, what do we make of Hume's claim that we "judge of the distance"? How could we judge of something that is not there? To address the first question we need to look at another passage in Treatise 
1.2.5, where Hume is explaining how we mistakenly believe we can form an idea of empty space.

After Hume discusses the case of the luminous bodies separated by darkness and its tangible analogue, he sets out to explain "why we falsely imagine we can form the idea of a vacuum" ( $\mathrm{T}$ 1.2.5.15; SBN 58). He mentions several similarities between the two kinds of distance he identifies: real extension and invisible and intangible distance. I focus here on his discussion of how our organs are affected, for as I have remarked earlier, it is only in the context of this discussion that he refers to the invisible and intangible distance as imaginary and fictitious. Hume claims that the "sensation of motion is ... the same, when there is nothing tangible interpos'd betwixt two bodies, as when we feel a compounded body, whose different parts are plac'd beyond each other" (T 1.2.5.15; SBN 58). Here Hume is comparing the sensation of the motion of the hands in a case of the interrupted tangible experience with the sensation of the motion of hands as they touch a "compounded body." Hume claims that the sensation of motion is the same. In the case of a compounded body, the motion of the hand is guided by the tangible feeling, as, for instance, when one moves one's hand along a smooth table. It is this guided sensation of motion that allows us to judge of the (real) distance. The case of interrupted tangible experience shares the feature that the movement of the hand is also guided in a way by the tangible. If it is something horizontal that one is touching, upon being interrupted, one would continue to move one's hand in a horizontal direction, expecting to find something in the same horizontal line as the previous object or tangible sensation. And here too then, the "guided" motion of the hand would allow us to judge of the distance.

However, in the case of interrupted tangible experience, the motion of the hand is not guided by the tangible, but by a tendency of the mind to move in the same direction or, more generally, "to go on as before." The same tendency is involved in the case of the fiction by which we suppose an "imaginary standard of equality." Hume says that the fiction is very natural, "nor is any thing more usual, than for the mind to proceed after this manner with any action, even after the reason has ceas'd, which first determin'd it to begin" (T 1.2.4.24; SBN 63). And in Treatise 1.4.2, Hume compares the tendency of the mind in the case of equality with the tendency of the mind that gives rise to the opinion of the continued existence of body: "the imagination, when set into any train of thinking, is apt to continue, even when its object fails it, and like a galley put in motion by the oars, carries on its course without any new impulse" (T 1.4.2.22; SBN 198). Thus we can perhaps say that in the case of interrupted tangibility, the hand, having been set in motion by the tangible object, continues even when the object fails it, or without the continued impulse of the tangible.

My point about "guided" motion can be strengthened by addressing the second question above: How can we judge of something that is not there? If there 
is no distance between the luminous bodies, how can we judge of the distance? Indeed, how can we refer to its size, "great or small"? How can Hume distinguish between two kinds of distance? Compare the following: observing someone making a pizza and observing a very good pantomime of someone making a pizza. All the movements are the same: the mixing of the ingredients, the rolling of the dough, the throwing the dough in the air, spreading the tomato sauce, adding cheese and pepperoni, placing the pizza in the oven. Of course, in the case of the pantomime, there is nothing there to mix or roll or throw or add, no tomato, no cheese, no pepperoni, no oven. But the movements are identical in the two cases, and so we describe both cases in the same way: rolling the dough, even when there is no dough and adding the pepperoni, even when there is no pepperoni. Note that we can "judge of the pizza" in the pantomime case, we can even judge the size of the pizza, without there being a pizza at all. Although there is no pizza, it is true that the pantomimist is making a pizza, and it is false that she is making a doughnut. And just as there is no pizza in the pantomime case, there is no distance in the case of the invisible and intangible distance. The invisible and intangible pizza is not a pizza, and the invisible and intangible distance is not a distance.

Toward the end of Treatise 1.2.5 Hume summarizes the results of this section and offers a positive account of the invisible and intangible distance:

Tho' there be nothing visible or tangible interpos'd betwixt two bodies, yet we find by experience, that the bodies may be plac'd in the same manner, with regard to the eye, and require the same motion of the hand in passing from one to the other, as if divided by something visible and tangible. This invisible and intangible distance is also found by experience to contain a capacity of receiving body, or of becoming visible and tangible. Here is the whole of my system; and in no part of it have I endeavour'd to explain the cause, which separates bodies after this manner, and gives them a capacity of receiving others betwixt them, without impulse or penetration. (T 1.2.5.25; SBN 63)

Hume goes on to clarify that explaining the cause which separates bodies after the above manner is "an enterprize that is beyond the reach of human understanding," and that our theorizing cannot go beyond experience (T 1.2.5.26; SBN 64). So what, according to experience, is an invisible and intangible distance? In the passage above Hume identifies two features. The second is that it is something that has "the capacity of receiving body or of becoming visible and tangible." The first feature, which makes reference to the eye and the motion of the hand is best captured in the following passage: 
[I]f it be ask'd, whether the invisible and intangible distance, interpos'd betwixt two objects, be something or nothing: 'Tis easy to answer, that it is something, viz. a property of the objects, which affect the senses after such a particular manner. (T 1.2.5.26n 12; SBN 638-39)

Thus the invisible and intangible distance has the capacity of receiving body, or of becoming visible and tangible, and it is a property of objects that affects our senses in a particular manner. The same can be said of the invisible and intangible pizza. It has the capacity of receiving pizza and, if it be asked, whether the invisible and intangible pizza is something or nothing, we could say that it is something, namely "a property" of the hands of the pantomimist that "affect our senses after such a particular manner."

No interpreter seems to have defended the view that the invisible and intangible distance is not a distance. Kemp Smith recognizes the distinction between (real) distance, or extension, which is sensed and the invisible and intangible distance, which is judged. But he conceives of both of them as things we "apprehend," as things that are there for us to grasp either through the senses or through judgment. ${ }^{9}$ He fails to realize that the judged distance is not a distance at all. So does Lorne Falkenstein, who insists on the sense/judge distinction. ${ }^{10}$ In contrast, Marina Frasca-Spada has argued that both real and imaginary distances are judged; both are manners of appearance, the imaginary one being a "radicalization of manners of appearance." 11 But there are a few problems with Frasca-Spada's interpretation. First, there is no good textual evidence that real distance is not sensed for Hume. ${ }^{12}$ And second, it seems that in Frasca-Spada's account Hume's own distinction between "real extension," on the one hand, and "imaginary distance" or "fictitious distance," on the other, loses its point. So it does in Baxter's account, according to which both distances, real and imaginary, appear to us (Baxter, 139). Finally, Costa defends the view that Hume "allows that the world itself might contain invisible and intangible 'distance' and moreover that he is inclined to think that it does because such a view accords with common sense and a right understanding of Newtonian philosophy."13

Costa's comment provides a bridge between the discussion so far and the question of the relation between Hume's denial of the idea of a vacuum and his position with respect to the existence of vacuum itself. A number of interpreters maintain that Hume allows for the possibility and even believes that there are vacuums in nature. In the next section, I discuss the textual grounds for this common interpretation and provide a different reading of the relevant texts. In the third section, I relate the standard claim that Hume allows for the possibility of vacuums in nature to a general, programmatic interpretation of Hume's work in the Treatise as mainly a descriptive science of mind. Finally, I suggest a different picture of Hume's project in the Treatise. 
The question of whether or not a true void, or vacuum, was possible was a central one in the seventeenth- and eighteenth-century debates in natural philosophy concerning the nature of space, time, and motion. Hume's discussion of the idea of vacuum makes sense against this intellectual background. But it is hard to make sense of Hume's contributions to this background if he denies that we have an idea of a vacuum yet concedes that there are vacuums in nature. Indeed, it is difficult to understand what import Hume's lengthy discussion of the idea of vacuum could have if the standard reading is correct. I shall next examine the texts that have fuelled the standard interpretation.

Interpreters who claim that Hume accepts the existence of a vacuum in nature quote the following passage in support of their view:

[I]f it be ask'd, whether or not the invisible or intangible distance be always full of body, or of something that by an improvement of our organs might become visible or tangible: I must acknowledge, that I find no very decisive arguments on either side; tho' I am inclin'd to the contrary opinion, as being more suitable to vulgar and popular notions. If the Newtonian philosophy be rightly understood, it will be found to mean no more. A vacuum is asserted: That is, bodies are said to be plac'd after such a manner, as to receive bodies betwixt them, without impulsion or penetration. (T 1.2.5.26n12; SBN 638-39)

Tycerium Lightner appeals to this passage as evidence for his claim that, although Hume declares that a vacuum is inconceivable, he is "inclined to think that there actually is a vacuum." ${ }^{14}$ David Norton interprets this passage as evidence that Hume "is more inclined to believe, as ordinary people do, that there are vacuums (that there are empty spaces) even though we have no idea of a vacuum." ${ }^{15}$ Don Garrett, too, appeals to the passage cited above and insists that when Hume acknowledges that we can place a body between bodies without impulse or penetration, he is thereby conceding that there is a vacuum. Hume is granting this because "this is precisely what the defenders of the vacuum have maintained." 16

I have several responses to these interpretative claims. The first concerns Norton's comment about ordinary people and their beliefs. Although, as Norton points out, the view that the vulgar obviously believed in the existence of a vacuum was not uncommon in Hume's time, I think one ought to be careful about imputing to ordinary people views about vacuums. ${ }^{17}$ There is certainly a difference between the vulgar belief in vacuum and the philosophical concept of a vaccum. It seems wrong to claim that ordinary people are committed to the existence of a philosophical vacuum when a bird flies into a room and they do not perceive any 
impulse or penetration. Although ordinary people believe that there are empty spaces between bodies, what they mean by "empty space" is probably quite compatible with the existence of air or Cartesian subtle matter. If Hume believes in vacuums, he does not believe in vacuums "as ordinary people do."

Second, does Hume allow or believe in vacuums because he denies that the invisible and intangible distance is full of body? Let us assume, against what I have argued in the first part of this paper, that when Hume denies that the invisible and intangible distance is full of body, he is committed to the view that there is an empty space, or vacuum, between the luminous bodies. Does this mean that Hume is committed to the existence of the very thing that he denies we have an idea of? No, even if we have an impression (or an idea) of two luminous bodies separated by empty space, or a vacuum, the idea Hume denies we have is the "idea of a vacuum, or space, where there is nothing visible or tangible" (T 1.2.5.1; SBN 53; my emphases). The idea of two luminous bodies separated by empty space is not the idea of space devoid of all content.

Now it might be argued that if Hume takes the luminous bodies to be separated by empty space, then we only need to subtract the luminous bodies to get the idea of space, or extension, devoid of all content..$^{18}$ But recall that Hume claims "that 'tis not from the mere removal of visible objects we receive the impression of extension without matter" (T 1.2.5.5; SBN 55) and "darkness and motion, with the utter removal of every thing visible and tangible, can never give us the idea of extension without matter or of a vacuum" (T 1.2.5.6; SBN 56). If you remove the luminous bodies, what you end up with, according to Hume, is utter darkness, not empty space, or a vacuum. So, even if Hume were committed to the existence of empty space between the luminous bodies, it is misleading to say that he is so committed even though he claims we have no idea of a vacuum. But, as I argued in the first part of the paper, the invisible and intangible distance which separates the luminous bodies is not a distance, empty space, or a vacuum. It is, instead, a property of objects that affects our senses in a particular manner and a capacity for receiving bodies. If this is the case, Hume can deny that the invisible and intangible distance is full of body without thereby being forced to admit that it is empty space, or a vacuum.

Third, is Hume granting that there is a vacuum when he allows that we can place bodies between other bodies without impulsion or penetration? Referring to this comment of Hume's, Garrett says: "it is potentially misleading . . . to describe Hume as denying that we can conceive of any such thing as a vacuum." It is potentially misleading because Hume "is inclined to agree (and thereby implies that he can conceive) that there are real situations that would permit the interjection of additional bodies without either 'impulsion or penetration' .... And this is precisely what the defenders of the vacuum have maintained" (Garrett, Cognition, 55). Now Garrett does not indicate who these defenders are, but what 
these defenders perhaps lack is the benefit of Hume's account of the invisible and intangible distance. As we saw earlier, Hume claims that the invisible and intangible distance to which he refers at the beginning of the passage cited above from T 1.2.5.26n12 (SBN 638-39) has "a capacity of receiving body, or of becoming visible and tangible," a capacity which he explicitly identifies with the capacity of receiving bodies "without impulse or penetration" (T 1.2.5.25; SBN 63). Contra Garrett, Hume is not committed to the existence of a vacuum when he acknowledges that we can place bodies between other bodies without impulse or penetration. He is just committed to his account of the invisible and intangible distance. It is true that Hume uses the word "vacuum" when he refers to the Newtonians in T 1.2.5.26n12 (SBN 638-39). But what is the point he is making? It seems that he is claiming that all that the Newtonian posit of a vacuum amounts to is the claim that we have observed that we can place bodies between other bodies without impulse or penetration. Hume's attitude toward the vacuum here is similar, I think, to the one he takes in the following passage:

If it be ask'd whether two objects, having such a distance [the invisible and intangible distance] betwixt them, touch or not: It may be answer'd, that this depends upon the definition of the word, touch. If objects be said to touch, when there is nothing sensible interpos'd betwixt them, these objects touch: If objects be said to touch, when their images strike contiguous parts of the eye, and when the hand feels both objects successively, without any interpos'd motion, these objects do not touch. (T 1.2.5.26n12; SBN 638-39)

If all that we mean by a "vacuum" is that we can place bodies between other bodies without impulsion or penetration, then Hume allows that there are vacuums. Is Hume "conceding" anything here? No, he is just acknowledging the facts of observation or experience and calling these facts a "vacuum." The interesting question then is not what is Hume conceding, but rather, what import, if any, does Hume's denial of the idea of a vacuum have for Newtonian philosophy? I shall address this question in the next section where I discuss what I take to be Hume's chief intention in the Treatise.

\section{III}

The main question in this section regards "Hume's intentions" in the Treatise. As John Passmore notes, there appear to be many intentions. ${ }^{19}$ But the one interpretation of Hume that many scholars today favor is that of Hume as a descriptive cognitive scientist, or as a "mental geographer," to invoke once again Hume's phrase from the Enquiry. According to this reading, Hume is principally engaged 
in an examination of the nature of our ideas and the processes of reasoning, and his discoveries within his domain of inquiry are not meant to have implications for the other sciences.

David Norton, for instance, claims that the reason why "Hume's conclusions in Treatise 1.2 leave virtually untouched the longstanding metaphysical puzzles about space and time" is that Hume's goal is "that of giving an account of the origin and nature of our ideas of space and time" (emphasis in the original). ${ }^{20}$ Norton seems to believe that Hume's discussion of the ideas of space and time has very little relation to the claims he makes about space and time themselves. The implications of such a view are numerous and important, but to focus on one that is particularly vivid, consider the following. If Norton is right, then Treatise 1.2.1, "Of the infinite divisibility of our ideas of space and time," and Treatise 1.2.2, "Of the infinite divisibility of space and time," would seem to be unrelated.

Consider also Garrett's comment about Hume's denial of the idea of a vacuum: "there is no idea of a vacuum and no impression from which such an idea can be derived. This conclusion," Garrett maintains, "is much less philosophically pregnant than it might appear. It is a claim about representations, made within a cognitive science of representations, and it has no negative consequences for those who deny that the universe is a plenum" (Garrett, 54). The implicit inference in Garrett's comment seems to be this: because Hume's rejection of the idea of a vacuum is made within his "cognitive science of representations," it has little philosophical import. Indeed, the last sentence seemingly suggests that it has no philosophical significance. And it would follow that if this is the case with the idea of vacuum, it would also be the case with all the other ideas Hume examines in the Treatise.

Let me now highlight another intention of Hume, one that unfortunately has not received much attention in Hume scholarship, but it is one that gives his examination of our ideas philosophical punch. This is the project Hume announces in the introduction to the Treatise, namely, to establish a "compleat system of the sciences, built on a foundation almost entirely new, and the only one upon which they can stand with any security" (T Intro 6; SBN xvi). The intention, Hume makes clear, is to establish a solid and secure foundation for the sciences by grounding them on his science of man or science of the mind. In the Abstract Hume confirms this project, asserting in its preface that "were his philosophy received, we must alter from the foundation the greatest part of the sciences" (Pref. 2; SBN 643). And in the Abstract itself he concludes: "This treatise therefore of human nature seems intended for a system of the sciences" (Abs. 3; SBN 646).

When we look at the content of the Treatise, especially Book 1, we see that Hume is not just interested in our ideas. Book 1 indicates an undeniable concern with the other sciences: the infinite divisibility of space and time (not just of our ideas of space and time, but space and time themselves, this difference being marked in 
the very titles of the first two sections of Treatise 1.2); the postulation of a vacuum, in particular, the role it plays in Newtonian philosophy; the science of geometry, a discussion Hume considers fundamental to mathematics, for he claims to have put into question the very "foundation of mathematics" (T 1.4.2.22; SBN 198); causal reasoning and necessary connection (where one of the key questions is whether or not there is necessity in nature).

Taking Hume's foundational intention seriously allows us to make sense of why he is concerned to examine the particular ideas he does, including the idea of a vacuum. It also allows us to make sense of the classifications he establishes within the mind and his attitude towards them. Why are there such things as fictions in Hume's science of mind? And why does Hume speak of the products of the imagination and fictions in a derogatory manner? For instance, Hume claims that the fiction of perfect equality is "useless as well as incomprehensible" (T 1.2.4.24; SBN 47). If Hume were merely engaged in a descriptive science of mind, he would limit himself to distinguishing the ideas derived from the senses from the products of the imagination. But he would not demote some and elevate others.

Although Hume endorses the employment of the Copy Principle as a criterion of meaning, he never claims that the word "vacuum" is meaningless. ${ }^{21}$ Indeed, his discussion of space and vacuum does not seem at all concerned with terms and their signification. Hume maintains that a vacuum, or empty space, is inconceivable: we cannot form an idea of a vacuum. But what is the "lesson" he wants the sciences to draw from this result? To answer this question, I want to call attention to another much less known principle of Hume's. We can call it the "no reason to believe" principle. At the end of his discussion of the idea of necessity, Hume draws the following corollary: "we can never have reason to believe that any object exists, of which we cannot form an idea" (T 1.3.14.36; SBN 172). This is an epistemic normative principle. If we cannot form an idea of $\mathrm{x}$, we have no reason to believe in the existence of $\mathrm{x}$. There is no justification for postulating entities of which we cannot form an idea.

Hume does not appeal to the "no reason to believe" principle explicitly in his discussion of the vacuum, but there is good reason for why he does not. The reason, in short, is that he has not given yet an account of how we form beliefs in the unobserved and when we are justified in believing something that is unobserved. These questions are the main subjects of Treatise 1.3, and in the passage where he introduces the "no reason to believe" principle, Hume offers a summary of his results. He claims that only causation can support "reasonings concerning existence," that causation depends on experience of conjunctions of objects, and that "the same experience must give us a notion of these objects" ( $\mathrm{T}$ 1.3.14.36; SBN 172). According to Hume, then, we can only learn of the existence of objects through experience, and causal reasoning alone, which depends essentially on experience, can give us reason to believe in the existence of unobserved objects. We 
have no experience (or impression) of the necessary connection between objects, and therefore, we have no reason to believe in it. The same reasoning applies to the case of a vacuum. We have not, and we cannot have, an impression of a vacuum. A vacuum is not merely unobserved; it is unobservable. We cannot form an idea of a vacuum, and therefore, according to the "no reason to believe" principle, we have no reason to believe in its existence.

In De Gravitatione, Newton maintains that we can "conceive of space existing without any subject when we think of a vacuum." 22 Hume's claims throughout Treatise 1.2 make it absolutely clear that he disagrees with Newton on this point. However, we might argue that Newton also takes himself to have empirical evidence for the existence of a vacuum. Newton might argue that the existence of a vacuum is demonstrable from phenomena (for instance, from the centrifugal forces generated in truly rotating bodies). ${ }^{23}$ This is what I take Hume's "no reason to believe" principle to disallow. We are not justified in positing objects or entities on such grounds. According to the "no reason to believe" principle, a necessary condition for positing something that is unobserved is that we can form an idea of it.

I want to distinguish my position from what seems to be Garrett's position. Although, as we saw earlier, Garrett claims that Hume's denial of the idea of a vacuum is not philosophically pregnant, at the end of his discussion of Hume's denial of the idea of a vacuum, Garrett writes, "Hume's position is best expressed not as the claim that there is no such thing as a vacuum but rather as the claim that there is no such (conceivable) thing as a vacuum - that is, empty absolute space-playing a substantive role in our ontology" (Garrett, 55). This conclusion is puzzling because if the claim that empty absolute space does not play a substantive role in our ontology follows from Hume's denial of the idea of a vacuum, then Hume's denial of the idea of a vacuum is indeed philosophically pregnant. But setting that aside, Garrett takes the conclusion that "there is no such (conceivable) thing as a vacuum" to be compatible with the position of those who deny that the universe is a plenum. For Garrett, we are justified in positing the existence of a vacuum or vacuums (although not the existence of the thing vacuum). In my account we are not justified in positing the existence of a vacuum.

So, where does Hume stand in relation to the Newtonian vacuum? Hume acknowledges that we can place bodies between other bodies without the observation of impulsion or penetration. If we want to give this empirical fact the name "vacuum," there is little harm in doing so. But what we cannot do is posit the existence of a thing, in this case a vacuum, that causally explains the empirical facts. Hume explicitly rejects such attempt in Treatise 1.2.5 when he says, "Here is the whole of my system; and in no part of it have I endeavour'd to explain the cause, which separates bodies after this manner, and gives them a capacity of receiving others betwixt them, without impulse or penetration" (T 1.2.5.25; SBN 63; my emphases). 
Hume's main criticism of Newtonian philosophy with respect to the vacuum is this: we cannot appeal to a vacuum as the cause of the observed phenomena, and we cannot do this because we cannot form an idea of a vacuum, or empty space. This follows directly from Hume's "no reason to believe" principle, and is suggested by several comments he makes in Treatise 1.2.5.

For instance, Hume writes "my intention never was to penetrate into the nature of bodies, or explain the secret causes of their operations. For besides that this belongs not to my present purpose, I am afraid, such an enterprize is beyond the reach of human understanding, and that we can never pretend to know body otherwise than by those external properties, which discover themselves to the senses" (T 1.2.5.26; SBN 64). He also remarks, "As long as we confine our speculations to the appearances of objects to our senses, without entering into disquisitions concerning their real nature and operations, we are safe from all difficulties, and can never be embarrass'd by any question" (T 1.2.5.26n12; SBN 638-39).

Consistent with these passages, Hume is not offering a new metaphysical account of the nature of vacuum. Nor is he claiming that there is no such thing as a vacuum or that a vacuum is impossible. Hume's criticism of Newtonian philosophy with respect to the vacuum concerns its philosophy of science; in particular, it concerns the question of when we are, and when we are not, justified in positing new entities in our theories.(Perhaps this difference rests on a yet more fundamental one, namely, their views on conceivability and of what it is to have an idea.) This is in line with Hume's foundational project, the project that aims to establish the sciences on a new foundation, namely his science of mind. Hume's science of mind has discovered that we cannot form an idea of a vacuum, or empty space. And Hume's "no reason to believe" principle establishes strict limits on when we can posit objects or entities in our theories. We cannot infer the existence of an object from phenomena when we cannot form an idea of that object. Hume is offering the sciences a method by which to determine when and how to restrain their theorizing, a method for ascertaining whether the claims they make about nature are justified. By doing so, he can be seen as delivering on his promise to establish the sciences on a solid and secure foundation. ${ }^{24}$

\section{Conclusion}

Treatise 1.2.5 presents the reader of Hume with a number of apparent inconsistencies and puzzles. In this paper, I have attempted to address two difficulties. First, Hume starts Treatise 1.2.5 with an argument to the effect that it is impossible for us to form an idea of a vacuum or an idea of empty space. Hume's denial of the idea of a vacuum follows from his account of the idea of space as the idea of "visible or tangible points distributed in a certain order" (T 1.2.5.1; SBN 53). In an attempt to demonstrate that there are, indeed, no experiences that can generate the idea 
of an empty space or a vacuum, Hume introduces the idea of an "invisible and intangible distance." If the idea of an invisible and intangible distance is the idea of a distance, as interpreters take it to be, then, it seems, it must be the idea of an empty distance, or a vacuum. And if that is the case, then Hume's account of our idea of space is mistaken. I have argued in this paper that the idea of an invisible and intangible distance is not the idea of a distance at all. Thus, Hume is not inconsistent when he denies that we have an idea of a vacuum and yet allows that we have an idea of an invisible and intangible distance.

Second, although Hume denies that we can form an idea of a vacuum, interpreters have found some texts in Treatise 1.2.5 to suggest strongly that he is nonetheless inclined to believe that there are vacuums in nature. If these interpreters are right, then we are faced with the general methodological question regarding Hume's aims in the Treatise. What is the point of Hume's discussion of ideas? In particular, what is the point of his denial of the idea of a vacuum? Some interpreters have answered these questions by confining Hume's discussion of ideas within a descriptive science of mind. In response, I have discussed the relevant texts, and I have defended the view that Hume does not believe that there is such a thing as empty space, or a vacuum, in nature. He is only committed to what he says: we can place bodies between other bodies without impulse or penetration. At the end of the paper, I have outlined an interpretation of Hume's project in the Treatise that allows us to understand his discussion of ideas as having implications for the other sciences, such as mathematics and natural philosophy.

\section{NOTES}

I thank Margaret Atherton, Bill Bristow, Don Garrett, Fabrizio Mondadori, Bob Schwartz, Joshua Spencer, Corliss Swain, Richard Tierney, Saul Traiger, and two anonymous reviewers for helpful comments and criticisms.

1 References to the Treatise are to David Hume, A Treatise of Human Nature, ed. David Fate Norton and Mary J. Norton (New York: Oxford University Press, 2011), hereafter cited as " $\mathrm{T}$ " followed by Book, part, section, and paragraph numbers; and to $A$ Treatise of Human Nature, ed. L. A. Selby-Bigge, revised by P. H. Nidditch, 2nd ed. (Oxford: Clarendon Press, 1978), hereafter cited as "SBN" followed by page number. References to the first Enquiry are to David Hume, An Enquiry concerning Human Understanding, ed. Tom L. Beauchamp (Oxford: Oxford University Press, 2006), hereafter cited as "EHU" followed by section and paragraph; and to An Enquiry Concerning Human Understanding, ed. L. A. Selby-Bigge, revised by P. H. Nidditch, 3rd ed. (Oxford: Clarendon Press, 1975), hereafter "ECHU" followed by page number.

2 For instance, David Norton says that Hume "is more inclined to believe, as ordinary people do, that there are vacuums (that there are empty spaces) even though we have 
no idea of a vacuum (David Hume, A Treatise of Human Nature, ed. D. F. and M. Norton (Oxford: Oxford University Press, 2008), 444n25.

3 It might be immediately objected that although similar questions may be raised concerning Hume's attitude toward external objects and necessary connections, some interpreters find Hume's use of certain terms like supposition or notion or relative idea to provide an answer to the question of how Hume can believe in external objects and necessary connection without having the relevant ideas. See, for instance, John Wright, The Sceptical Realism of David Hume (Manchester: Manchester University Press, 1983); Galen Strawson, The Secret Connexion: Causation, Realism and David Hume (Oxford: Clarendon Press, 1989); Michael Costa, "Hume and Causal Realism," Australasian Journal of Philosophy 67 (1989): 172-90; and Janet Broughton, "Hume's Ideas about Necessary Connection," Hume Studies 13 (1987): 217-44. This interpretational move is highly controversial (I myself am not persuaded), but in any case, it cannot be applied to the present case, because Hume never claims that we suppose or have a notion or a relative idea of a vacuum, and it seems far-fetched to argue that the belief in a vacuum is a "natural belief."

4 Assuming that the idea of an invisible and intangible distance must, in the end, be the same as the idea of a vacuum, or empty space, Henry Allison has recently accused Hume of committing a "petitio principi." According to Allison, Hume attempts to explain our mistake in believing that we have an idea of empty space by appealing to the idea of invisible and intangible distance, but in so doing he "presupposes that we already have an idea of such an empty space, which is the very thing that Hume wants to deny being possible." Without an account of how or why the invisible and intangible distance is not the same as empty space or vacuum, Allison's reaction is indeed the natural one. Henry Allison, Custom and Reason in Hume: A Kantian Reading of the First Book of the Treatise (Oxford University Press, 2008), 57.

5 Donald Baxter, "Hume's Theory of Space and Time in its Skeptical Context," in The Cambridge Companion to Hume, ed. David Fate Norton and Jacqueline Taylor, 2nd ed. (Cambridge: Cambridge University Press, 2009), 105-46, 142.

6 There is just one line in Treatise 1.2.5 where Hume mentions that the invisible distance is "without parts, without composition, invariable and indivisible" (T 1.2.5.11; SBN 57).

7 Michael J. Costa, "Hume, Strict Identity, and Time's Vacuum," Hume Studies 16 (1990): 1-16, 5 .

8 See T 1.2.5.3 (SBN 54) for this objection.

9 Norman Kemp Smith, The Philosophy of David Hume (London: Macmillan Press, 1941), 310-11.

10 Lorne Falkenstein, "Review of Marina Frasca-Spada's Space and the Self in Hume's Treatise," Hume Studies 25 (1999): 241-49, 247.

11 Marina Frasca-Spada, Space and the Self in Hume's Treatise (Cambridge: Cambridge University Press, 1998), 178-84.

12 Falkestein makes this point against Frasca-Spada, 247-48. 
13 Michael Costa, "Hume and Causal Inference," Hume Studies 12 (1986): 141-59, 156-57.

14 D. Tycerium Lightner, "Hume on Conceivability and Inconceivability," Hume Studies 23 (1997): 113-32, 123.

15 Norton and Norton, Treatise (2008), 444n25.

16 Don Garrett, Cognition and Commitment in Hume's Philosophy (Oxford University Press, 1997), 55.

17 Norton and Norton, Treatise (2011), 727.

18 I thank one of the anonymous reviewers for raising this objection.

19 John Passmore, Hume's Intentions (Cambridge University Press, 1952).

20 Norton and Norton, Treatise (2008), I24.

21 For explicit statements of Hume's endorsement of the Copy Principle as a criterion of meaning see, for instance, Abs. 7 (SBN 648) and EHU 2.9 (SBN 21), although exactly what meaning and function the copy principle has in Hume's philosophy is a much debated issue in the literature.

22 Isaac Newton, De Gravitatione, in Newton, Philosophical Writings, ed. Andrew Janiak (Cambridge University Press, 2004), 33.

23 Robert DiSalle discusses how Newton takes the notion of absolute space to be demonstrable from phenomena. Robert DiSalle, "Newton's Philosophical Analysis of Space and Time," in The Cambridge Companion to Newton, ed. I. B. Cohen and G. Smith (Cambridge: Cambridge University Press, 2002), 33-56. I thank one of the anonymous reviewers for pointing this particular example out to me.

24 I offer a fuller discussion of the nature of Hume's foundational project in "Hume's Foundational Project in the Treatise," forthcoming in European Journal of Philosophy. 
